\title{
A crosstalk between type 2 innate lymphoid cells and alternative macrophages in lung development and lung diseases (Review)
}

\author{
LAN-LAN MI ${ }^{1 *}, \mathrm{YUE} \mathrm{ZHU}^{1 *}$ and HONG-YAN LU ${ }^{1,2}$ \\ ${ }^{1}$ Department of Pediatrics, The Affiliated Hospital of Jiangsu University, Zhenjiang, Jiangsu 212001; \\ ${ }^{2}$ International Genome Center, Jiangsu University, Zhenjiang, Jiangsu 212013, P.R. China
}

Received October 29, 2020; Accepted March 8, 2021

DOI: $10.3892 / \mathrm{mmr} .2021 .12042$

\begin{abstract}
Type 2 innate lymphoid cells (ILC2s) are important innate immune cells that are involved in type 2 inflammation, in both mice and humans. ILC2s are stimulated by factors, including interleukin (IL)-33 and IL-25, and activated ILC2s secrete several cytokines that mediate type 2 immunity by inducing profound changes in physiology, including activation of alternative (M2) macrophages. M2 macrophages possess immune modulatory, phagocytic, tissue repair and remodeling properties, and can regulate ILC2s under infection. The present review summarizes the role of ILC2s as innate cells and M2 macrophages as anti-inflammatory cells, and discusses current literature on their important biological significance. The present review also highlights how the crosstalk between ILC2s and M2 macrophages contributes to lung development, induces pulmonary parasitic expulsion, exacerbates pulmonary viral and fungal infections and allergic airway diseases, and promotes the development of lung diseases, such as pulmonary fibrosis, chronic obstructive pulmonary disease and carcinoma of the lungs.
\end{abstract}

\section{Contents}

1. Introduction

2. ILC2s

3. M2 macrophages

4. Crosstalk between ILC2s and M2 macrophages during lung development

5. Crosstalk between ILC2s and M2 macrophages in lung diseases

6. Conclusions and perspective

Correspondence to: Professor Hong-Yan Lu, Department of Pediatrics, The Affiliated Hospital of Jiangsu University, 438 Jiefang Road, Zhenjiang, Jiangsu 212001, P.R. China

E-mail: hylu@ujs.edu.cn

*Contributed equally

Key words: type 2 innate lymphoid cells, alternative macrophages, crosstalk, lung development, lung diseases

\section{Introduction}

Lung development initiates in utero and continues until infancy, and involves a complex process regulated by different types of cells, factors and mediators, such as macrophages, dendritic cells and lymphocytes (1). Abnormal lung development can be harmful to respiratory health, which may result in bronchopulmonary dysplasia, neonatal respiratory distress syndrome, asthma and chronic obstructive emphysema (2-4). Type 2 immune response is important for pulmonary development and several types of pulmonary diseases, such as asthma, lung infection and pulmonary fibrosis (5-7).

Interleukin (IL)-4, IL-5, IL-9 and IL-13 are important cytokines that play key roles in type 2 immunity, and are usually involved in allergic diseases or during helminthic parasitic infections $(8,9)$. Th2 cells and certain myeloid cells are considered the primary source of these type 2 cytokines $(10,11)$; however, recent studies have reported that a rare subpopulation of innate lymphocytes are the predominant source (12-14). Type 2 innate lymphoid cells (ILC2s), which were first discovered as non-T and B cells $(15,16)$, play a defensive role in the initial stage of helminthic infestation (17), and are considered a major component of type 2 immunity in lungs $(18,19)$.

Several types of cells, including eosinophils, mast cells, basophils and alternative (M2) macrophages, activated by IL-4 and IL-13 that are involved in type 2 immune response, also regulate the repair response following tissue injury (20). M2 macrophages initiate different responses to parasites, tissue remodeling, angiogenesis and allergic diseases (21-23). Therefore, it may be hypothesized that M2 macrophages can crosstalk with ILC2s during pulmonary development and in different pulmonary diseases.

\section{ILC2s}

ILCs are innate immune cells that regulate mucosal immune response (24). ILCs are important effector cells in the innate immune system (25). In addition to acting as first-line defense against pathogen invasion and infection, ILCs are also involved in lymphoid organ formation, tissue repair and mucosal homeostasis (26).

ILC2s are a subset of ILCs, and activation of these produce several Th2 cytokines, including IL-4, IL-5, IL-9 
and IL-13, and/or dual-regulatory proteins, such as amphiregulin (AREG) (27). ILC2s depend on transcription factors, GATA binding protein 3 and retinoid acid receptor related orphan receptor $\alpha$, for their development and function, but lack antigen-specific receptors $(28,29)$. ILC2s are distributed throughout the body and are abundant on mucosal surfaces, such as the lungs, gastrointestinal tract and skin, in both humans and mice (30). ILC2s account for a major proportion in mouse pulmonary innate lymphocytes, and $<3 \%$ of human lung innate lymphocytes $(31,32)$.

Lung ILC2s are rapidly activated when exposed to epithelial-derived alarmin proteins and other inflammatory mediators, including IL-33, IL-25 and thymic stromal lymphopoietin (TSLP) (33). A previous study demonstrated that IL-25 reactive lung ILC2s can change into IL-33 reactive lung ILC2s, both in vivo and in vitro (34). IL-33 and IL-25 both promote the enrichment of ILC2s in lung in vivo; however, only IL-33 can directly induce the migration of ILC2s in vitro (35). Similar effects of IL-33 are observed in skin (36), while TSLP and IL-25 exhibit relatively poor chemotaxis, although they can be detected at high concentrations in lungs $(37,38)$.

Although ILC2s secrete IL-9, autocrine IL-9 maintains homeostasis of pulmonary ILC2s $(37,38)$. IL-2 was the first cytokine reported to promote the secretion of IL-9 by ILC2s (39). IL-2 is also important for activating and culturing ILC2s in vitro $(39,40)$. Another study demonstrated that IL-4 can increase IL-9 expression by stimulating ILC2s (41). Suppression of IL-9 production inhibits IL-33-induced eosinophilic airway inflammation, highlighting its role in effectively proliferating and activating ILC2s (42). In addition, the synergistic effects of TSLP and IL-33 markedly effect the production of IL-9 via ILC2s (37).

ILC2s express corresponding receptors, including suppression of tumorigenicity 2 (ST2), IL-25R (IL-17RB), TSLPR and AREG receptor, as well as toll-like receptors (TLRs) 2 and 4 (28,29,43-45). Upon activation, excluding Th2-type cytokines and/or AREG, ILC2s also secrete other factors, including granulocyte-macrophage colony stimulating factor (GM-CSF), IL-6 and IL-10 (46-48). In addition to stimulators, there are also inhibitors of ILC2s. For example, the neuropeptide calcitonin gene-related peptide and its receptor can inhibit the secretion and enrichment of pulmonary ILC2s and Th2 cytokines driven by alarmin, both in vitro and in vivo (49).

Elevated numbers of ILC2s in patients with asthma and chronic sinusitis suggest that ILC2s are detrimental to chronic inflammation (50). However, intrahepatic ILC2s can exacerbate fibrosis in liver diseases by secreting AREG (51). Thus, the roles of ILC2s vary in different tissues and diseases, and involve complex molecular mechanisms.

Recently, ILC2s have become the research focus in different tissue and organ diseases. It has been reported that intestinal helminthic infection induces activation of ILC2s, proliferation of IL-13 dependent goblet cells and increases mucin production at distal sites, including the lungs (52). In severe cases, increased mucus secretion via alveoli and the lungs inhibits lung metastasis (52). This suggests that the innate immunity of ILC2s is not only limited to certain tissues, but also influences and interacts with different organs. According to a previous study, aging influences innate immunity (53). ILC2s in elderly lungs are not uniform in transcription and function, and cannot produce cytokines during influenza infection and homeostasis in vivo (53). The transfer of ILC2s in the lungs of young mice strengthens the immunity of old mice to influenza infection (53). Notably, ILC2s in neonatal lungs involve distinct pro-inflammatory and tissue repair subgroups (54). Neonatal endogenous IL-33 stimulates ILC2s in the pulmonary, which may 'train' ILC2s for implantation into the lungs following birth, thus becoming resident cells that respond more effectively to future challenges (55). Thus, by secretion of a plethora of mediators, ILC2s play vital roles in inducing and supporting type 2 immune responses in lung tissues.

\section{M2 macrophages}

Macrophages, which act as myeloid cells, are among the first cells that respond to pathogens and tissue damage (56). They not only have innate immune function, which acts by phagocytizing and killing pathogens directly to exert innate immunity, but also initiate adaptive immunity by presenting pathogens to $\mathrm{T}$ lymphocytes $(57,58)$. Tissue macrophages, which are important immune cells, are produced by yolk sac or fetal liver and their function is guided by resident tissues (59). Thus, it is important to study the macrophages that reside in the lung to understand the role of macrophages in lung diseases. There are two subtypes based on anatomical position of pulmonary resident macrophages, alveolar macrophages (AMs) and interstitial macrophages (60).

AMs, which are the most important resident macrophages in the lung, act as immune barriers in the alveoli against several pathogens of the respiratory tract (61). Alveolar macrophages are highly heterogeneous and exhibit unique phenotypes and functions in the complex microenvironment of the body (62). They are non-polarized under normal conditions (63). However, macrophages are induced and polarized into classical activation (M1) or alternate activation (M2) phenotypes under the stimulation of inflammation or in different immune development stages $(64,65)$. These also play a role in producing different chemokines and cytokines in the local microenvironment (66).

M2 macrophages are predominantly induced by cytokines, including IL-4, IL-10 and IL-13, glucocorticoids and immune complexes TLRs (67). Similar to ILC2s, they can also induce typical Th2 cytokines to decrease inflammatory response by promoting angiogenesis, tissue repairing, remodeling and wound healing (68). In addition, excessive tissue repair and remodeling results in fibrosis, which can aggravate the condition (69). M2 macrophages highly express type I arginase encoding genes (arginase-1, Arg1) and mannose receptor (CD206), and thus the expression and activity of Arg1 and CD206 are used to identify M2 macrophages (70). Under the induction of memory Th2 cells, M2 macrophages, which are important immune effector cells, can scavenge pathogens, which is associated with Arg1 activity (71). M2 macrophages have a weak antigen-presenting capacity compared with M1 macrophages, and downregulate the immune response by secreting inhibitory cytokines, such as IL-10 and/or tumor growth factor $\beta$ (TGF- $\beta$ ) (72). A different type of M 2 macrophage exists in the tumor site, which can be induced by IL-10 and is affected by chemokines, including CCL2, M-CSF and vascular endothelial growth factor (58). 


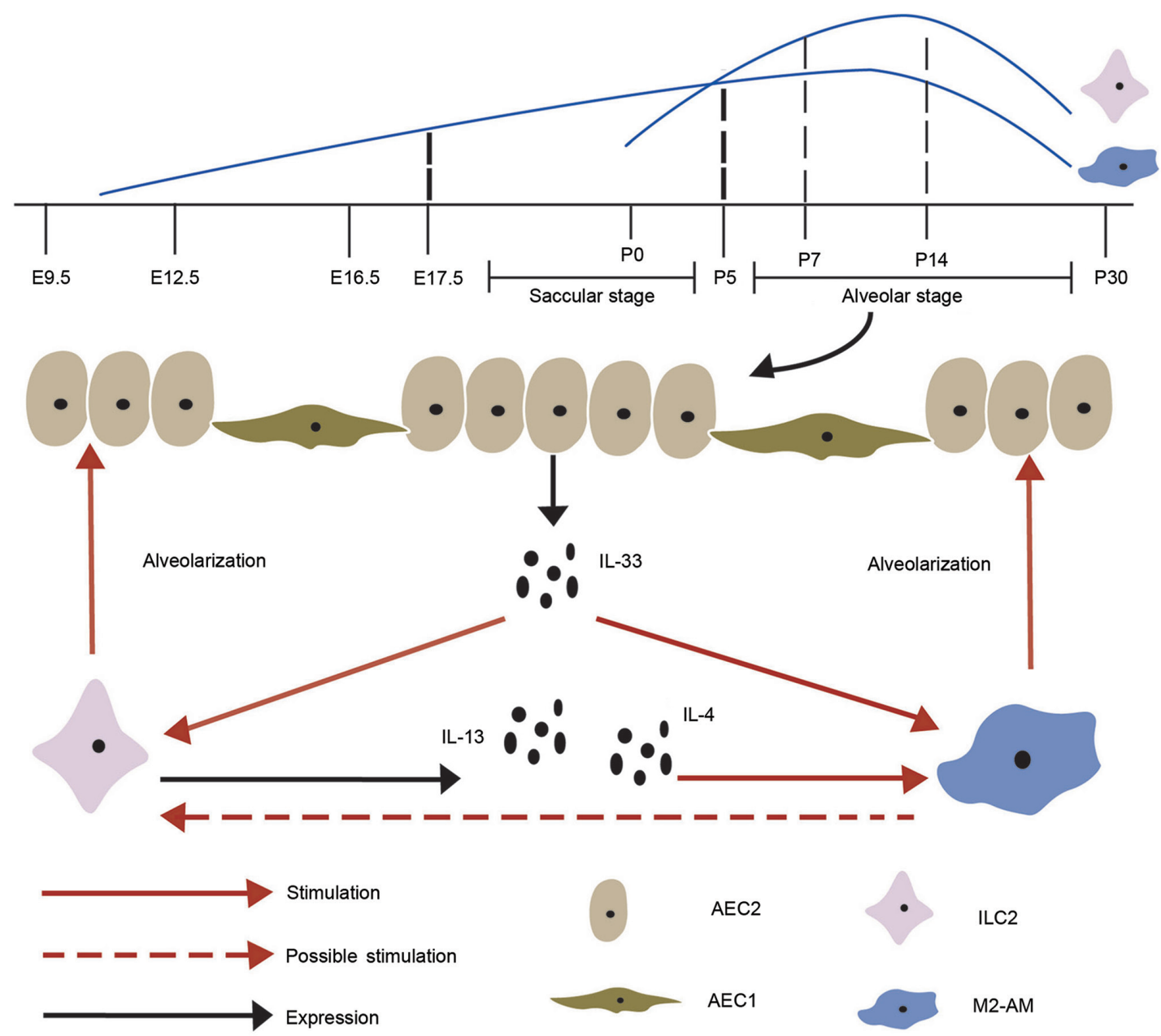

Figure 1. Quantitative changes of ILC2s and M2 macrophages in lung development and the effect of crosstalk on alveolarization. ILC2, type 2 innate lymphoid cell; M2-AM, alternative macrophage; IL, interleukin; AM, alveolar macrophage; AEC1, type 1 alveolar epithelial cell; AEC2, type 2 alveolar epithelial cell.

\section{Crosstalk between ILC2s and M2 macrophages during lung development}

The developmental process of lungs involves complex steps in humans/mice, and is subdivided into five stages, embryonic, pseudoglandular,canalicular, saccularand alveolar (73). Among these, the vesicle [Embryo day(E)16-E266/E17.5-Postnatal day (P)5] and alveolar (E252-2 years/P5-P30) stages are important as they affect the development and maturity of lungs (Fig. 1) (73). Macrophages first appear on day 10 of pregnancy and can be continuously detected during fetal lung development (74), which then increases with alveolarization $(75,76)$. The perinatal period is a critical window for transferring and distributing congenital immune cells to all the tissues and organs during lung development (77). ILC2s, which are similar to tissue macrophages, also appear during pregnancy, but at a later stage, and most of the peripheral ILC2 pools are produced de novo following birth (77). Several studies have confirmed that rapid amplification and activation of ILC2s in pulmonary occur during the early postnatal period (78-80). Pulmonary resident ILC2s are minimal at birth, increase during alveolarization, reach peak at 7-14 days and subsequently decrease in adulthood, similar to AMs (76,81-83). Thus, the interactions between ILC2s and macrophages most likely occur during the vesicle and alveolar stages. Gradually, fewer ILC2s in lung tissues are replaced by newly generated ILC2s, but the expanded ILC2s during the early postnatal period account for the majority of adult lung ILC2s (77).

From the very start, the lung is exposed to the external environment (84). The microenvironment of the lung undergoes a notable change within a short period of time and requires rapid regulation to avoid inflammatory response caused by environmental stimulation (84). After being stimulated during labor, IL-33 rapidly increases and activates ILC2s in the fluid filled lung and begins to promote the formation of type 2 immune environment in pulmonary tissues (76). Type 2 immunity involves type 2 cytokines, eosinophilia, mucogenesis, IgE and M2 macrophages (85). The presence of AMs is consistent with that of IL-13-secreting ILC2s, which exhibit IL-13 dependent anti-inflammatory M2-type in the early stage of lung development (76). It has also been reported that IL-4 receptor $\alpha$ (IL-4R $\alpha$ ), including IL-4 and IL-13, can promote AMs to polarize into M2 macrophages, suggesting that the crosstalk between ILC2s and M2 macrophages plays a role in regulating type 2 immunity $(86,87)$. Another study demonstrated that the addition of ILC2s can make AMs express more M2 macrophages-related markers in vitro (88). Postnatal adaptation to breathing depends on pulmonary surfactant being synthesized and secreted by type 2 alveolar epithelial cells (AEC2) (89). Promoted by M2 macrophages, 
AEC2 continuously proliferate and differentiate to accelerate alveolar formation (90).

A previous study revealed that M2 macrophages are enriched in lung tissues and AEC2 proliferated rapidly following pneumonectomy (91). ILC2s increase and become the main source of IL-13, which induces AMs to differentiate into M2 phenotype (91). Both IL-4R $\alpha$-expressing ILC2s and M2 macrophages, which are necessary for optimal lung regeneration, promote the regeneration of lung tissues by stimulating the growth of AEC2 (91). Rindler et al (92) reported that M2 macrophages are clustered together and localized in the site of AEC2 multiplication during regeneration.

It has been reported that activation of IL-33 can promote type 2 immunity in pulmonary development by amplifying and activating ILC2s during the perinatal period (81). IL-4, IL-5 and IL-13 exhibit upregulation after activation of ILC2s, which constitutively express ST2. In addition to activating ILC2s, IL-33 also stimulate the expression and polarization of AMs by basophils during alveolar formation $(93,94)$. Thus, it is hypothesized that IL-33 promotes proliferation and activation of ILC2s and M2 macrophages during lung development, and crosstalk between ILC2s and M2 macrophages promotes alveolarization. This is consistent with the IL-33-ST2 axis regulating regeneration of epithelial through activation of monocyte differentiation into reparative M2 macrophages and ILC2s-mediated M2 macrophages (95). In summary, ILC2s promote the polarization of M2 macrophages via IL-4/13. In addition to IL-4/13, there may be other associations between ILC2s and M2 macrophages in the complex process of embryonic development, which have not been fully investigated. Thus, future studies are required to determine how M2 macrophages directly affect ILC2s, and how their crosstalk promotes fetal and preterm lung development.

\section{Crosstalk between ILC2s and M2 macrophages in lung diseases}

The arrest of alveolar development or disruption of alveolar structure is not only associated with neonatal respiratory distress syndrome, bronchopulmonary dysplasia and persistent pulmonary hypertension, but also chronic lung diseases, such as asthma, allergic diseases and chronic obstructive pulmonary emphysema (2-4). Pulmonary epithelial barrier dysfunction is an important pathological component of lung injury, which is mainly caused by damage of epithelial cell migration (96). ILC2s participate in the regulation of AEC2 and different lung diseases (37). M2 macrophages are a subgroup of macrophages whose polarization is important for AEC2 regulation and inflammatory response (97). Thus, the crosstalk between increased ILC2s and upregulated M2 macrophages may regulate lung development, and modulate the processes of several lung diseases (Fig. 2).

Pulmonary parasitic infection. Several parasites, namely pulmonary parasitic diseases, spread to other parts of the human body via blood circulation, and often reside in the lungs, causing pathological changes (98). The host cells of helminth mega parasites are involved in type 2 immune response, including Th2 cells and type 2 cytokines (IL-4, IL-5, IL-9 and IL-13), which are required to fight these pathogens $(99,100)$.
Recently, it has been reported that the relative abundance of these macrophages and the rare ILC2s have a swift and strong response to helminth antigen and helminth induced injury, activating damaged epithelial cells and recruiting other effector factors (101). Immunocompromised larvae of helminths have a significant morphological defect, which is affected by aggregation of IL-13-secreting ILC2s and CD4 ${ }^{+}$ $\mathrm{T}$ cells, and the polarization of M2 macrophages (102). Application of IL-2 or IL-33 can bypass the requirement of $\mathrm{T}$ cells, resulting in proliferation of IL-13 and secretion of ILC2s and death of larvae, and exhaustion of ILC2s inhibits larval death in mice by transferring IL-2 (102). Thus, it is not surprising that ILC2s are the key factor during infection and are maintained by $\mathrm{CD} 4^{+} \mathrm{T}$ cells, which not only ensure rapid activation of IL-13 dependent M2 macrophages, but also maintain their immune function in lung tissues (102).

Amp activated protein kinase (AMPK) is a significant driving factor of cellular energy, which exists in AMs (103). Deletion of AMPK decreases the secretion of IL-13 and impairs the expansion of ILC2s in lung tissues from mice that are selectively deprived of $\alpha 1$ subunit, thereby exacerbating lung injury following ancylostoma infection (103). Surfactant protein D (SP-D) is an important epithelial product (104). Increased levels of pulmonary SP-D before infection can enhance parasite excretion and type 2 immune response, including the increase of IL-13-producing ILC2s, M2 macrophages and the cytokines, IL-4 and IL-13 (104). Thus, it is speculated that AMs and ILC2s assist in coordinating the regulation of mucosal tissue damage through metabolic enzyme function $(103,104)$.

Pulmonary viral and fungal infections. Several studies have confirmed that the intensity of infection is affected by type 1 immune response and polarization of M1 macrophages, while type 2 immunity and polarization of M2 macrophages are closely associated with disease progression and adverse outcomes (105-107). In infected lungs, the number of ILC2s significantly increase following induction of type 2 response (108). ILC2-deficient mice exhibit a notable declination in type 2 immune response 14 days after infection, which is characterized by decreased expression levels of IL-4, IL-5 and IL-13, as well as the number of M2 macrophages (108).

The change in polarization of pulmonary macrophages in ILC2-deficient mice is frequently associated with better control of fungi and prolongation of survival time of infected mice (108). Rhinovirus (RV) infection also induces IL-25, IL-33, IL-4, IL-5, IL-13 and ILC2s expansion, mucus metaplasia and airway hyperresponsiveness (109). IL-1 $\beta$ of pulmonary macrophages inhibits type 2 inflammation and mucus metaplasia following RV infection by decreasing ILC2s and cytokines (109).

Group V phospholipase A2 (Pla2g5) is a lipid-producing enzyme that is required for macrophage functioning in lung inflammation (110). Macrophages also assist in regulating IL-33 induction and free fatty acids (FFAs)-driven ILC2s activation via Pla2g5, significantly contributing to type-2 immunity (110). In addition, mass spectrometry analysis demonstrated significant reduction of FFAs in Pla2g5 deficient lung tissues and BM-macrophages in Alternaria-exposed wild-type mice (110). 


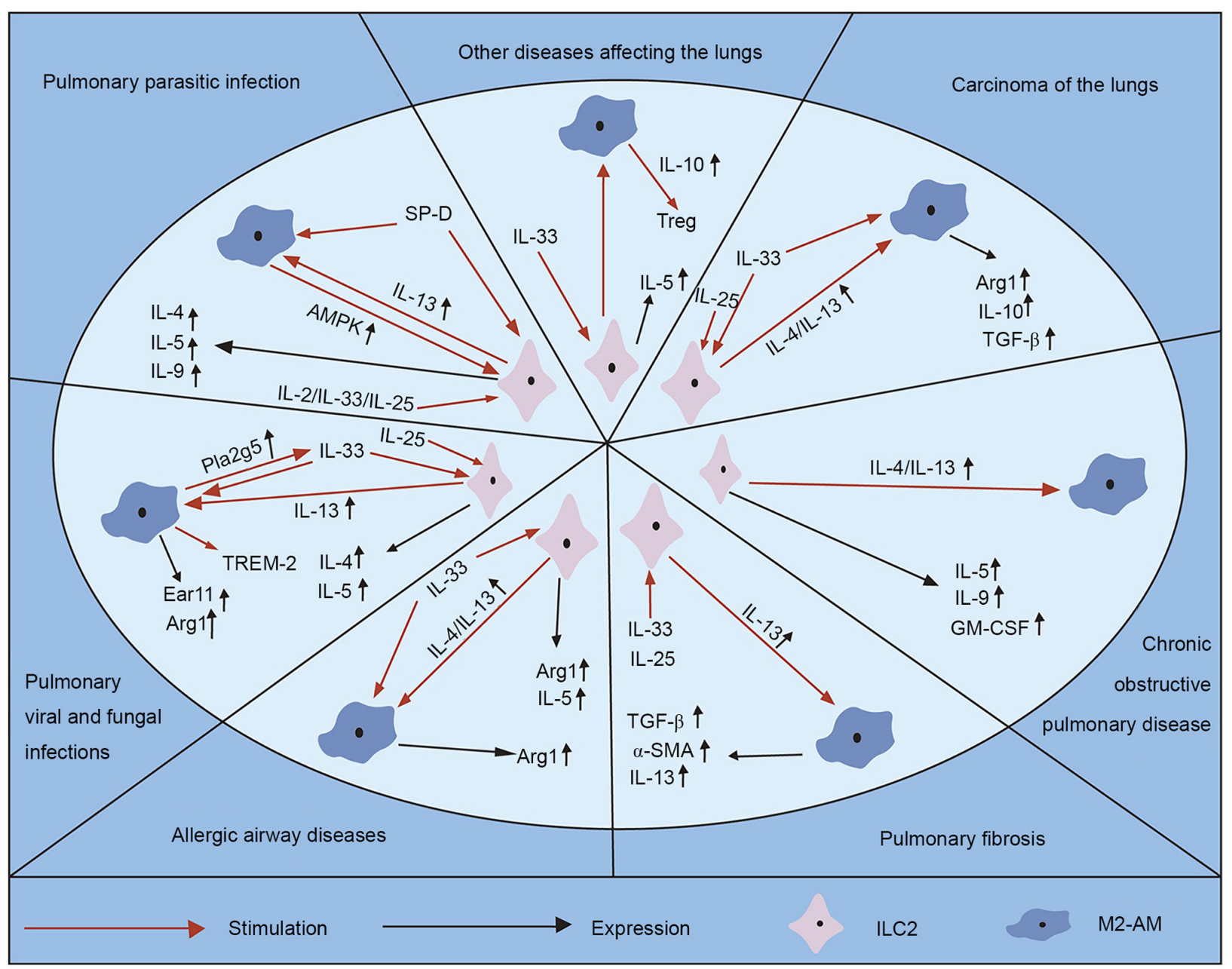

Figure 2. Crosstalk between ILC2s and M2 macrophages regulates type 2 immune response in lung diseases. ILC2, type 2 innate lymphoid cell; M2-AM, alternative macrophage; IL, interleukin; AMPK, Amp activated protein kinase; SP-D, surfactant protein D; TGF- $\beta$, tumor growth factor $\beta$; TREM- 2 , triggering receptors on myeloid cell 2; Pla2g5, group V phospholipase A2; Ear11, eosinophil-associated ribonuclease 11; GM-CSF, granulocyte-macrophage colony stimulating factor.

Another study reported that type 2 immunoregulatory neutrophil infiltration is influenced by mouse eosinophil associated ribonuclease 11, and is secreted by M2 macrophages downstream of ILC2s that are stimulated by IL-25 (111). Furthermore, neutrophils can promote type 2 immune response without aggravating inflammation (111).

Chronic post viral disease is characterized by excessive airway mucus formation and multiplication of M2 differentiated pulmonary macrophages, requiring expression of macrophages for triggering receptors on myeloid cell 2 (TREM-2) (112). With increasing levels of IL-13, virus replication increases the levels of macrophages and TREM-2 in the lung tissues, preventing macrophage apoptosis in acute diseases (112). Following infection clearance, IL-13 promotes cleavage of TREM-2 into the soluble form, STREM-2, which prevents macrophage apoptosis (112). These results may explain how crosstalk between ILC2s with M2 macrophages in acute infection results in chronic inflammatory diseases.

Recruitment of neutrophils, eosinophils and inflammatory chemokines (KC, eotaxin-1, MIP1a and MIP1b), Th2 cytokines (IL-4/5), arginase-1 (M2 macrophage marker) and IL-33R+ ILC2s cells are significantly elevated in adenovirus Oncostatin M (OSM) mice, while these responses are significantly attenuated in IL-33-/- mice (113). In vitro, IL-33 upregulates OSM expression in RAW264.7 macrophage cells and bone marrow-derived macrophages (113). Thus, IL-33 is a key mediator of OSM-driven lung inflammation, induction of type 2 immune responses and M2 macrophages in mice, which contributes via activation of ILC2s (113).

Allergic airway diseases ( $A A D)$. In addition to the common tissue tropism, AAD also have obvious inflammatory patterns, including eosinophils, M2 macrophages, ILC2s, IgE secreting B cells and Th2 cells, and cytokines, including IL-33, IL-4, IL-5 and IL-13 $(114,115)$. Reduction of Th2 cytokines (IL-4, IL-5 and IL-13), macrophages, ILC2s and other cells in lung tissues, and alveolar lavage fluid, can improve allergic airway inflammation in mice, which may be a potential way to treat allergic asthma $(58,116)$.

Arg1, produced by M2 macrophages, can regulate asthma and allergic inflammation (117). A study demonstrated that compared with M2 macrophages expressing Arg1 after activation of STAT6 mediated by IL-4/13, ILC2s constitutively express Arg1 in a STAT6-independent manner (117). IL-33 can affect Arg1 in lung tissues by promoting the proliferation of ILC2s and indirectly activating macrophages via STAT6 (117). These results further highlight that ILC2s 
and M2 macrophages have a synergistic regulatory effect on asthma and allergic inflammation via Arg1.

During allergic response, the selective depletion of E3 ligase VHL in innate lymphoid progenitor cells increases hypoxia inducible factor- $1 \alpha$ (HIF-1 $\alpha$ ) expression, which in turn decreases ST2 and inhibits the development of ILC2s induced by IL-33 via epigenetic modification (118). HIF-1 $\alpha$ affects glycolysis and phenotype of macrophages (119), suggesting that HIF-1 $\alpha$ acts through the regulation of ILC2s and macrophages during allergic reaction.

Lung ILC2s exhibit an inverse correlation with $\mathrm{MHC}-\mathrm{II}^{\text {high }}$ resident macrophages (M1), and a positive correlation with MHC-II ${ }^{\text {low }}$ resident macrophages (M2), and their contribution to AAD induced by HDM may also be affected by heredity (120). Notably, ILC2s, which are amateur antigen presenting cells (121), cooperate with macrophages to form and regulate adaptive immunity to allergens and helminth (121).

Pulmonary fibrosis. Idiopathic pulmonary fibrosis is characterized by fibroblast aggregation, collagen deposition and extracellular matrix remodeling, in which myofibroblasts are considered effector cells (72). In the pulmonary fibrosis model, AMs were recruited into the alveoli, and the phenotype involves M2 macrophages, which upregulates CD206 on the cell surface (72). In vitro, 264.7 cells treated with IL-4 were used as M2 macrophages, and the TGF- $\beta$ levels in the supernatant significantly increased. $\alpha$-SMA expression increased following co-culturing of lung epithelial cells (MLE-12) with M2 macrophages, suggesting that M2 macrophages regulate pulmonary fibrosis by inducing epithelial-to-mesenchymal transition (72).

In addition to the increase of M2 macrophages, the increase of IL-33, IL-13, TGF- $\beta 1$ and inflammatory chemokines are also observed during pulmonary fibrosis (122). IL-13 and TGF- $\beta 1$ are produced by M2 macrophages, and IL-13 is secreted by ILC2s, both in vivo and in vitro, and induced by IL-33 (122). As IL-13 can induce the polarization of M2 macrophages (123), a cycle where IL-13 can be produced by M2 macrophages and promotes polarization of M2 macrophages is formed. IL-33 sends signals through ST2, and recruits and guides inflammatory cell function in ST2- and macrophage-dependent manners, and enhances the generation of pro-fibrosis cytokines, thus promoting the occurrence and development of pulmonary fibrosis (122).

Zhao et al (124) reported that bone marrow-derived ILC2s accumulate in the fibrotic lung and activated fibroblasts to promote pulmonary fibrosis by inducing the IL-33/ST2 signaling pathway. In addition, ILC2s are induced by IL-25, which results in significant changes in the pathological process of pulmonary fibrosis through the production of IL-13 (125). Thus, the application of anti-IL-33 antibody and depletion of AMs or ILC2s may be potential therapeutic methods for pulmonary inflammation and fibrosis.

Chronic obstructive pulmonary disease (COPD). A clinical study demonstrated that normal AMs are mainly nonpolarized (63). However, the polarization of M1 and M2 macrophages significantly enhances, and the co-expression of M1 and M2 markers in the same AMs also significantly increases, with the aggravation of smoking and COPD severity (63).
In human COPD, ILCs accumulate in lung tissues, with increasing signature cytokines, such as IL-5 and GM-CSF (126). The levels of neutrophil elastase and IL-5 increase in patients with acute exacerbation of COPD (127), and the levels of IL-13 mRNA in eosinophils and endothelial cells in the sputum also increase to about 30 times (128). In addition, Th2 cytokine IL-9 can also aggravate lung injury by activating STAT3 in COPD mice and increasing inflammation and oxidative stress (129).

For the interaction of STIP1 homology and U-box-1 (STUB1), IL-4R $\alpha$ is used as the target, which prevents IL-4 or IL-13 signal transduction via ubiquitination mediated proteasome degradation (130). In STUB1-deficient mice, spontaneous airway inflammation increases IL-4R $\alpha$ expression, STAT6 is continuously activated, M2 macrophages are activated and serum IgE increases (130). The level of STUB1 in the airway of patients with asthma or COPD increases, suggesting that upregulation of STUB1 may be an important feedback mechanism for inhibiting IL-4R signal transduction in airway inflammation (130).

Carcinoma of the lungs. In different tumors, type 2 immune responses induce polarization of M2 macrophages, which in turn enhances the invasion and migration of tumor cells by secreting Arg1, IL-10 and TGF- $\beta(107,131,132)$. The progression of lung cancer is associated with poor patient prognosis and high mortality (133). The survival rate of tumor-bearing mice with vitamin A deficiency diet is low, and the tumor size increases with increasing number of type 2 cytokines, ILC2s and M2 macrophages in BALF of mice, suggesting that ILC2s and polarized M2 macrophages play a synergistic role in promoting cancer progression (133). This synergistic effect may be accomplished via two pathways, the co-promotion of ILC2s and M2-type macrophages by IL-33 (134-136), and the promotion of M2 macrophage polarization by type 2 cytokines $(123,137)$, such as IL-4 and IL-13, secreted by ILC2s (138). This is consistent with the fact that both M2 subtype macrophages (M2a and M2b) and IL-25-stimulated ILC2s favor cancer progression (139). Notably, other substances that inhibit the polarization of M2 macrophages by IL-4/13 can change the tumor microenvironment (140). However, further studies are required to understand the crosstalk between ILC2s and M2 macrophages in lung cancer and determine their underlying molecular mechanisms.

Other diseases affecting the lungs. Sepsis is defined as life-threatening organ dysfunction caused by a dysregulated host response to infection (141). The lung is an extremely fragile organ that is prone to sepsis (142). In sepsis model with cecal ligation and puncture, IL-33 upregulates IL-5 in ILC2s, whereas IL-5 inhibits neutrophil and monocyte infiltration, suggesting that this axis is involved in lung injury early after sepsis (142). Survivors of sepsis will have chronically low immune functions (143). IL-33, which is produced following sepsis, activates ILC2s and promotes the polarization of M2 macrophages, thus accelerating the proliferation of Treg cells through IL-10 (143). Subsequently, increased ILC2s, M2 macrophages, IL-10 and Treg cells result in immunosuppression (143). 


\section{Conclusions and perspective}

Lung resident ILC2s are important immunoregulatory cells that are involved in metabolism, tissue repair and multiple organ remodeling, outlining a previously unanticipated role of type 2 immunity in regulating basal homeostasis. Similarly, macrophages are a group of pluripotent and plasticity immune cells, that also regulate type 2 immune response. In lungs, AMs and interstitial macrophages differentiate into different cell phenotypes at different stages of development, including M1 and M2 macrophages.

The proliferation and activation of ILC2s and M2 macrophages are consistent, and are not only involved in lung development, but also in lung diseases. In addition, ILC $2 \mathrm{~s}$ and M2 macrophages interact to regulate the lung microenvironment, which is effective in pulmonary development and pulmonary diseases. The crosstalk between IL-4R $\alpha$-expressing ILC2s and upregulated M2 macrophages produces remarkable effects in lung inflammation, allergy, tumor and fibrosis responses. Further studies are required to better understand the development, activation, turnover and interaction between ILC2s and M2 macrophages in lung tissues. Targeting the IL-33/ILC2s/M2-macrophage axis may be an effective novel approach for the treatment of several lung diseases.

\section{Acknowledgements}

Not applicable.

\section{Funding}

The present review was financially supported by the Natural Science Foundation of Jiangsu Province (grant no. BK20201226) and the Social Development Foundation of Zhenjiang, China (grant no. SH2020037).

\section{Availability of data and materials}

Not applicable.

\section{Authors' contributions}

LLM and HYL conceived the present study and performed the literature review. LLM and YZ collected and reviewed the literature, and drafted the initial manuscript. All authors confirm the authenticity of all the raw data and critically revised the manuscript for important intellectual content. LLM and YZ produced the figures. All authors have read and approved the final manuscript.

\section{Ethics approval and consent to participate}

Not applicable.

\section{Patient consent for publication}

Not applicable.

\section{Competing interests}

The authors declare that they have no competing interests.

\section{References}

1. Domingo-Gonzalez R, Zanini F, Che X, Liu M, Jones RC, Swift MA, Quake SR, Cornfield DN and Alvira CM: Diverse homeostatic and immunomodulatory roles of immune cells in the developing mouse lung at single cell resolution. Elife 9: e56890, 2020.

2. Martinez FD: Early-life origins of chronic obstructive pulmonary disease. N Engl J Med 375: 871-878, 2016.

3. Lange P, Celli B, Agusti A, Boje Jensen G, Divo M, Faner R, Guerra S, Marott JL, Martinez FD, Martinez-Camblor P, et al: Lung-function trajectories leading to chronic obstructive pulmonary disease. N Engl J Med 373: 111-122, 2015.

4. McGeachie MJ, Yates KP, Zhou X, Guo F, Sternberg AL, Van Natta ML, Wise RA, Szefler SJ, Sharma S, Kho AT, et al: Patterns of growth and decline in lung function in persistent childhood asthma. N Engl J Med 374: 1842-1852, 2016.

5. Loering S, Cameron GJM, Bhatt NP, Belz GT, Foster PS, Hansbro PM and Starkey MR: Differences in pulmonary group 2 innate lymphoid cells are dependent on mouse age, sex and strain. Immunol Cell Biol: Dec 8, 2020 (Epub ahead of print). doi: 10.1111/imcb.12430.

6. Lan F, Zhang N, Holtappels G, De Ruyck N, Krysko O, Van Crombruggen K, Braun H, Johnston SL, Papadopoulos NG, Zhang L and Bachert C: Staphylococcus aureus induces a mucosal type 2 immune response via epithelial cell-derived cytokines. Am J Respir Crit Care Med 198: 452-463, 2018.

7. Sciurba JC, Gieseck RL, Jiwrajka N, White SD, Karmele EP, Redes J, Vannella KM, Henderson NC, Wynn TA and Hart KM: Fibroblast-specific integrin-alpha V differentially regulates type 17 and type 2 driven inflammation and fibrosis. J Pathol 248: $16-29,2019$.

8. Hajimohammadi B, Athari SM, Abdollahi M, Vahedi G and Athari SS: Oral administration of acrylamide worsens the inflammatory responses in the airways of asthmatic mice through agitation of oxidative stress in the lungs. Front Immunol 11: 1940, 2020.

9. Ryan NM and Oghumu S: Role of mast cells in the generation of a T-helper type 2 dominated anti-helminthic immune response. Biosci Rep 39: BSR20181771, 2019.

10. Choi JP, Kim YM, Choi HI, Choi SJ, Park HT, Lee WH, Gho YS, Jee YK, Jeon SG and Kim YK: An important role of tumor necrosis factor receptor-2 on natural killer T cells on the development of dsRNA-enhanced Th2 cell response to inhaled allergens. Allergy 69: 186-198, 2014.

11. Sun L, Cornell TT, LeVine A, Berlin AA, Hinkovska-Galcheva V, Fleszar AJ,Lukacs NW and Shanley TP: Dual role of interleukin-10 in the regulation of respiratory syncitial virus (RSV)-induced lung inflammation. Clin Exp Immunol 172: 263-279, 2013.

12. Helou DG, Shafiei-Jahani P, Lo R, Howard E, Hurrell BP, Galle-Treger L, Painter JD, Lewis G, Soroosh P, Sharpe AH and Akbari O: PD-1 pathway regulates ILC2 metabolism and PD-1 agonist treatment ameliorates airway hyperreactivity. Nat Commun 11: 3998, 2020.

13. Leyva-Castillo JM, Galand C, Mashiko S, Bissonnette R, McGurk A, Ziegler SF, Dong C, McKenzie ANJ, Sarfati M and Geha RS: ILC2 activation by keratinocyte-derived IL-25 drives IL-13 production at sites of allergic skin inflammation. J Allergy Clin Immunol 145: 1606-1614.e4, 2020.

14. Miller MM, Patel PS, Bao K, Danhorn T, O'Connor BP and Reinhardt RL: BATF acts as an essential regulator of IL-25-responsive migratory ILC2 cell fate and function. Sci Immunol 5: eaay3994, 2020.

15. Fort MM, Cheung J, Yen D, Li J, Zurawski SM, Lo S, Menon S, Clifford T, Hunte B, Lesley R, et al: IL-25 induces IL-4, IL-5, and IL-13 and Th2-associated pathologies in vivo. Immunity 15: 985-995, 2001.

16. Hurst SD, Muchamuel T, Gorman DM, Gilbert JM, Clifford T, Kwan S, Menon S, Seymour B, Jackson C, Kung TT, et al: New IL-17 family members promote Th1 or Th2 responses in the lung: In vivo function of the novel cytokine IL-25. J Immunol 169: 443-453, 2002.

17. Oliphant CJ, Hwang YY, Walker JA, Salimi M, Wong SH, Brewer JM, Englezakis A, Barlow JL, Hams E, Scanlon ST, et al: MHCII-mediated dialog between group 2 innate lymphoid cells and CD4(+) T cells potentiates type 2 immunity and promotes parasitic helminth expulsion. Immunity 41: 283-295, 2014.

18. She L, Alanazi HH, Yan L, Brooks EG, Dube PH, Xiang Y, Zhang F, Sun Y, Liu Y, Zhang X and Li XD: Sensing and signaling of immunogenic extracellular RNAs restrain group 2 innate lymphoid cell-driven acute lung inflammation and airway hyperresponsiveness. PLoS One 15: e0236744, 2020. 
19. Entwistle LJ, Gregory LG, Oliver RA, Branchett WJ, Puttur F and Lloyd CM: Pulmonary group 2 innate lymphoid cell phenotype is context specific: Determining the effect of strain, location, and stimuli. Front Immunol 10: 3114, 2019.

20. Gieseck RL III, Wilson MS and Wynn TA: Type 2 immunity in tissue repair and fibrosis. Nat Rev Immunol 18: 62-76, 2018.

21. Katsura Y, Harada N, Harada S, Ishimori A, Makino F, Ito J, Kamachi F, Okumura K, Akiba H, Atsuta R and Takahashi K: Characteristics of alveolar macrophages from murine models of OVA-induced allergic airway inflammation and LPS-induced acute airway inflammation. Exp Lung Res 41: 370-382, 2015.

22. Fang SB, Zhang HY, Meng XC, Wang C, He BX, Peng YQ, Xu ZB, Fan XL, Wu ZJ, Wu ZC, et al: Small extracellular vesicles derived from human MSCs prevent allergic airway inflammation via immunomodulation on pulmonary macrophages. Cell Death Dis 11: 409, 2020.

23. Su B, Han H, Gong Y, Li X, Ji C, Yao J, Yang J, Hu W, Zhao W, Li J, et al: Let-7d inhibits intratumoral macrophage M2 polarization and subsequent tumor angiogenesis by targeting IL-13 and IL-10. Cancer Immunol Immunother: Nov 25, 2020 (Epub ahead of print). doi: 10.1007/s00262-020-02791-6.

24. De Salvo C, Buela KA and Pizarro TT: Cytokine-mediated regulation of innate lymphoid cell plasticity in gut mucosal immunity. Front Immunol 11: 585319, 2020.

25. Silver J, Humbles AA and Ohne Y: Isolation, culture, and induction of plasticity in ILC2s. Methods Mol Biol 2121: 115-127, 2020.

26. Vacca P, Chiossone L, Mingari MC and Moretta L: Heterogeneity of NK cells and other innate lymphoid cells in human and murine decidua. Front Immunol 10: 170, 2019.

27. Li S, Bostick JW, Ye J, Qiu J, Zhang B, Urban JF Jr, Avram D and Zhou L: Aryl hydrocarbon receptor signaling cell intrinsically inhibits intestinal group 2 innate lymphoid cell function. Immunity 49: 915-928.e5, 2018.

28. Klose CS and Artis D: Innate lymphoid cells as regulators of immunity, inflammation and tissue homeostasis. Nat Immunol 17: 765-774, 2016

29. Kabata H, Moro K and Koyasu S: The group 2 innate lymphoid cell (ILC2) regulatory network and its underlying mechanisms. Immunol Rev 286: 37-52, 2018.

30. Pasha MA, Patel G, Hopp R and Yang Q: Role of innate lymphoid cells in allergic diseases. Allergy Asthma Proc 40: 138-145, 2019.

31. Monticelli LA, Sonnenberg GF, Abt MC, Alenghat T, Ziegler CG, Doering TA, Angelosanto JM, Laidlaw BJ, Yang CY, Sathaliyawala T, et al: Innate lymphoid cells promote lung-tissue homeostasis after infection with influenza virus. Nat Immunol 12: 1045-1054, 2011.

32. Simoni Y, Fehlings M, Kloverpris HN, McGovern N, Koo SL, Loh CY, Lim S, Kurioka A, Fergusson JR, Tang CL, et al: Human innate lymphoid cell subsets possess tissue-type based heterogeneity in phenotype and frequency. Immunity 48: 1060, 2018.

33. Camelo A, Rosignoli G, Ohne Y, Stewart RA, Overed-Sayer C, Sleeman MA and May RD: IL-33, IL-25, and TSLP induce a distinct phenotypic and activation profile in human type 2 innate lymphoid cells. Blood Adv 1: 577-589, 2017.

34. Huang Y, Guo L, Qiu J, Chen X, Hu-Li J, Siebenlist U, Williamson PR, Urban JF Jr and Paul WE: IL-25-responsive, lineage-negative KLRG1(hi) cells are multipotential 'inflammatory' type 2 innate lymphoid cells. Nat Immunol 16: 161-169, 2015.

35. Li Y, Chen S, Chi Y, Yang Y, Chen X, Wang H, Lv Z, Wang J, Yuan L, Huang P, et al: Kinetics of the accumulation of group 2 innate lymphoid cells in IL-33-induced and IL-25-induced murine models of asthma: A potential role for the chemokine CXCL16. Cell Mol Immunol 16: 75-86, 2019.

36. Salimi M, Barlow JL, Saunders SP, Xue L, Gutowska-Owsiak D, Wang X, Huang LC, Johnson D, Scanlon ST, McKenzie AN, et al: A role for IL-25 and IL-33-driven type-2 innate lymphoid cells in atopic dermatitis. J Exp Med 210: 2939-2950, 2013.

37. Mohapatra A, Van Dyken SJ, Schneider C, Nussbaum JC, Liang HE and Locksley RM: Group 2 innate lymphoid cells utilize the IRF4-IL-9 module to coordinate epithelial cell maintenance of lung homeostasis. Mucosal Immunol 9: 275-286, 2016.

38. Moretti S, Renga G, Oikonomou V, Galosi C, Pariano M, Iannitti RG, Borghi M, Puccetti M, De Zuani M,Pucillo CE, et al A mast cell-ILC2-Th9 pathway promotes lung inflammation in cystic fibrosis. Nat Commun 8: 14017, 2017.

39. Wilhelm C, Hirota K, Stieglitz B, Van Snick J, Tolaini M, Lahl K, Sparwasser T, Helmby H and Stockinger B: An IL-9 fate reporter demonstrates the induction of an innate IL-9 response in lung inflammation. Nat Immunol 12: 1071-1077, 2011.
40. Bartemes KR, Kephart GM, Fox SJ and Kita H: Enhanced innate type 2 immune response in peripheral blood from patients with asthma. J Allergy Clin Immunol 134: 671-678.e4, 2014.

41. Motomura Y, Morita H, Moro K, Nakae S, Artis D, Endo TA, Kuroki Y, Ohara O, Koyasu S and Kubo M: Basophil-derived interleukin-4 controls the function of natural helper cells, a member of ILC2s, in lung inflammation. Immunity 40: 758-771, 2014.

42. Matsuki A, Takatori H, Makita S, Yokota M, Tamachi T, Suto A, Suzuki K, Hirose K and Nakajima H: T-bet inhibits innate lymphoid cell-mediated eosinophilic airway inflammation by suppressing IL-9 production. J Allergy Clin Immunol 139: 1355-1367.e6, 2017.

43. Zhang K, Jin Y, Lai D, Wang J, Wang Y, Wu X, Scott M, Li Y, Hou J, Billiar T, et al: RAGE-induced ILC2 expansion in acute lung injury due to haemorrhagic shock. Thorax 75: 209-219, 2020.

44. Ishii T, Muroi M, Horiguchi K, Tanamoto KI, Nagase T and Yamashita N: Activation through toll-like receptor 2 on group 2 innate lymphoid cells can induce asthmatic characteristics. Clin Exp Allergy 49: 1624-1632, 2019.

45. Maggi L, Montaini G, Mazzoni A, Rossettini B, Capone M, Rossi MC, Santarlasci V, Liotta F, Rossi O, Gallo O, et al: Human circulating group 2 innate lymphoid cells can express CD154 and promote IgE production. J Allergy Clin Immunol 139: 964-976. e4, 2017.

46. Gury-BenAri M, Thaiss CA, Serafini N, Winter DR, Giladi A, Lara-Astiaso D, Levy M, Salame TM, Weiner A, David E, et al: The spectrum and regulatory landscape of intestinal innate lymphoid cells are shaped by the microbiome. Cell 166: 1231-1246.e13, 2016.

47. Robinette ML, Fuchs A, Cortez VS, Lee JS, Wang Y, Durum SK, Gilfillan S and Colonna M; Immunological Genome Consortium: Transcriptional programs define molecular characteristics of innate lymphoid cell classes and subsets. Nat Immunol 16: 306-317, 2015.

48. Kim HS, Jang JH, Lee MB, Jung ID, Kim YM, Park YM and Choi WS: A novel IL-10-producing innate lymphoid cells (ILC10) in a contact hypersensitivity mouse model. BMB Rep 49: 293-296, 2016.

49. Wallrapp A, Burkett PR, Riesenfeld SJ, Kim SJ, Christian E, Abdulnour RE, Thakore PI, Schnell A, Lambden C, Herbst RH, et al: Calcitonin gene-related peptide negatively regulates alarmin-driven type 2 innate lymphoid cell responses. Immunity 51: 709-723.e6, 2019.

50. Ho J, Bailey M, Zaunders J, Mrad N, Sacks R, Sewell W and Harvey RJ: Group 2 innate lymphoid cells (ILC2s) are increased in chronic rhinosinusitis with nasal polyps or eosinophilia. Clin Exp Allergy 45: 394-403, 2015

51. Jeffery HC, McDowell P, Lutz P, Wawman RE, Roberts S, Bagnall C, Birtwistle J, Adams DH and Oo YH: Human intrahepatic ILC2 are IL-13positive amphiregulinpositive and their frequency correlates with model of end stage liver disease score. PLoS One 12: e0188649, 2017.

52. Campbell L, Hepworth MR, Whittingham-Dowd J, Thompson S, Bancroft AJ, Hayes KS, Shaw TN, Dickey BF, Flamar AL, Artis D, et al: ILC2s mediate systemic innate protection by priming mucus production at distal mucosal sites. J Exp Med 216: 2714-2723, 2019

53. D'Souza SS, Shen X, Fung ITH, Ye L, Kuentzel M, Chittur SV, Furuya Y, Siebel CW, Maillard IP, Metzger DW and Yang Q: Compartmentalized effects of aging on group 2 innate lymphoid cell development and function. Aging Cell 18: e13019, 2019.

54. Ghaedi M, Shen ZY, Orangi M, Martinez-Gonzalez I, Wei L, Lu X, Das A, Heravi-Moussavi A, Marra MA, Bhandoola A and Takei F: Single-cell analysis of ROR $\alpha$ tracer mouse lung reveals ILC progenitors and effector ILC2 subsets. J Exp Med 217: jem.20182293, 2020

55. Steer CA, Matha L, Shim H and Takei F: Lung group 2 innate lymphoid cells are trained by endogenous IL-33 in the neonatal period. JCI Insight 5: e135961, 2020.

56. Lindquist RL, Bayat-Sarmadi J, Leben R, Niesner R and Hauser AE: NAD $(\mathrm{P}) \mathrm{H}$ oxidase activity in the small intestine is predominantly found in enterocytes, not professional phagocytes. Int J Mol Sci 19: 1365, 2018.

57. Vellozo NS, Pereira-Marques ST, Cabral-Piccin MP, Filardy AA, Ribeiro-Gomes FL, Rigoni TS, DosReis GA and Lopes MF: All-trans retinoic acid promotes an M1- to M2-phenotype shift and inhibits macrophage-mediated immunity to leishmania major. Front Immunol 8: 1560, 2017. 
58. Moreira AP, Cavassani KA, Hullinger R, Rosada RS, Fong DJ, Murray L, Hesson DP and Hogaboam CM: Serum amyloid $\mathrm{P}$ attenuates M2 macrophage activation and protects against fungal spore-induced allergic airway disease. J Allergy Clin Immunol 126: 712-721.e7, 2010.

59. Wu Y and Hirschi KK: Tissue-resident macrophage development and function. Front Cell Dev Biol 8: 617879, 2020.

60. Liu G, Zhai H, Zhang T, Li S, Li N, Chen J, Gu M, Qin Z and Liu X: New therapeutic strategies for IPF: Based on the 'phagocytosis-secretion-immunization' network regulation mechanism of pulmonary macrophages. Biomed Pharmacother 118: 109230, 2019.

61. Li R, Shang Y, Hu X, Yu Y, Zhou T, Xiong W and Zou X: $\mathrm{ATP} / \mathrm{P} 2 \mathrm{X} 7 \mathrm{r}$ axis mediates the pathological process of allergic asthma by inducing M2 polarization of alveolar macrophages. Exp Cell Res 386: 111708, 2020.

62. Ke X, Chen C, Song Y, Cai Q, Li J, Tang Y, Han X, Qu W, Chen A, Wang H, et al: Hypoxia modifies the polarization of macrophages and their inflammatory microenvironment, and inhibits malignant behavior in cancer cells. Oncol Lett 18 5871-5878, 2019.

63. Bazzan E, Turato G, Tine M, Radu CM, Balestro E, Rigobello C, Biondini D, Schiavon M, Lunardi F, Baraldo S, et al: Dual polarization of human alveolar macrophages progressively increases with smoking and COPD severity. Respir Res 18: 40, 2017.

64. Lin F, Song C, Zeng Y, Li Y, Li H, Liu B, Dai M and Pan P: Canagliflozin alleviates LPS-induced acute lung injury by modulating alveolar macrophage polarization. Int Immunopharmacol 88: 106969, 2020.

65. Soliman E, Elhassanny AE, Malur A, McPeek M, Bell A Leffler N, Van Dross R, Jones JL, Malur AG and Thomassen MJ Impaired mitochondrial function of alveolar macrophages in carbon nanotube-induced chronic pulmonary granulomatous disease. Toxicology 445: 152598, 2020 .

66. Nenasheva T, Gerasimova T, Serdyuk Y, Grigor'eva E, Kosmiadi G, Nikolaev A, Dashinimaev E and Lyadova I: Macrophages derived from human induced pluripotent stem cells are low-activated 'Naive-Like' cells capable of restricting mycobacteria growth. Front Immunol 11: 1016, 2020.

67. Zhang L, Wang Y, Wu G, Xiong $\mathrm{W}, \mathrm{Gu} \mathrm{W}$ and Wang CY: Macrophages: Friend or foe in idiopathic pulmonary fibrosis? Respir Res 19: 170, 2018

68. Bronte V and Zanovello P: Regulation of immune responses by L-arginine metabolism. Nat Rev Immunol 5: 641-654, 2005.

69. Grabarz F, Aguiar CF, Correa-Costa M, Braga TT, Hyane MI, Andrade-Oliveira V, Landgraf MA and Camara NOS: Protective role of NKT cells and macrophage M2-driven phenotype in bleomycin-induced pulmonary fibrosis. Inflammopharmacology 26 491-504, 2018

70. de Campos GY, Oliveira RA, Oliveira-Brito PK, Roque-Barreira MC and da Silva TA: Pro-inflammatory response ensured by LPS and Pam3CSK4 in RAW 264.7 cells did not improve a fungistatic effect on Cryptococcus gattii infection. PeerJ 8: e10295, 2020.

71. Anthony RM, Urban JF Jr, Alem F, Hamed HA, Rozo CT, Boucher JL, Van Rooijen N and Gause WC: Memory T(H)2 cells induce alternatively activated macrophages to mediate protection against nematode parasites. Nat Med 12: 955-960, 2006.

72. Zhu L, Fu X, Chen X, Han X and Dong P: M2 macrophages induce EMT through the TGF-beta/Smad2 signaling pathway. Cell Biol Int 41: 960-968, 2017

73. Loering S, Cameron GJ, Starkey MR and Hansbro PM: Lung development and emerging roles for type 2 immunity. J Pathol 247: 686-696, 2019.

74. Blackwell TS, Hipps AN, Yamamoto Y, Han W, Barham WJ, Ostrowski MC, Yull FE and Prince LS: NF-kappaB signaling in fetal lung macrophages disrupts airway morphogenesis. J Immunol 187: 2740-2747, 2011.

75. Jones CV, Williams TM, Walker KA, Dickinson H, Sakkal S, Rumballe BA, Little MH, Jenkin G and Ricardo SD: M2 macrophage polarisation is associated with alveolar formation during postnatal lung development. Respir Res 14: 41, 2013.

76. Saluzzo S, Gorki AD, Rana BMJ, Martins R, Scanlon S, Starkl P, Lakovits K, Hladik A, Korosec A, Sharif O, et al: First-breath-induced type 2 pathways shape the lung immune environment. Cell Rep 18: 1893-1905, 2017.

77. Schneider C, Lee J,Koga S, Ricardo-Gonzalez RR, Nussbaum JC, Smith LK, Villeda SA, Liang HE and Locksley RM: Tissue-resident group 2 innate lymphoid cells differentiate by layered ontogeny and in situ perinatal priming. Immunity 50 : $1425-1438 . e 5,2019$.
78. Huang Y, Mao K, Chen X, Sun MA, Kawabe T, Li W, Usher N, Zhu J, Urban JF Jr, Paul WE and Germain RN: S1P-dependent interorgan trafficking of group 2 innate lymphoid cells supports host defense. Science 359: 114-119, 2018.

79. Steer CA, Martinez-Gonzalez I, Ghaedi M, Allinger P, Matha L and Takei F: Group 2 innate lymphoid cell activation in the neonatal lung drives type 2 immunity and allergen sensitization. J Allergy Clin Immunol 140: 593-595.e3, 2017.

80. Nussbaum JC, Van Dyken SJ, von Moltke J, Cheng LE, Mohapatra A, Molofsky AB, Thornton EE, Krummel MF, Chawla A, Liang HE and Locksley RM: Type 2 innate lymphoid cells control eosinophil homeostasis. Nature 502: 245-248, 2013.

81. de Kleer IM, Kool M, de Bruijn MJ, Willart M, van Moorleghem J, Schuijs MJ, Plantinga M, Beyaert R, Hams E, Fallon PG, et al: Perinatal activation of the interleukin-33 pathway promotes type 2 immunity in the developing lung. Immunity 45: 1285-1298, 2016.

82. Ghaedi M, Steer CA, Martinez-Gonzalez I, Halim TYF, Abraham N and Takei F: Common-lymphoid-progenitor-independent pathways of innate and T lymphocyte development. Cell Rep 15: 471-480, 2016

83. Sahoo D, Zaramela LS, Hernandez GE, Mai U, Taheri S, Dang D, Stouch AN, Medal RM, McCoy AM, Aschner JL, et al: Transcriptional profiling of lung macrophages identifies a predictive signature for inflammatory lung disease in preterm infants. Commun Biol 3: 259, 2020

84. Ubags NDJ, Alejandre Alcazar MA, Kallapur SG, Knapp S, Lanone S, Lloyd CM, Morty RE, Pattaroni C, Reynaert NL, Rottier RJ, et al: Early origins of lung disease: Towards an interdisciplinary approach. Eur Respir Rev 29: 200191, 2020.

85. Obata-Ninomiya K, Ishiwata K, Tsutsui H, Nei Y, Yoshikawa S, Kawano Y, Minegishi Y, Ohta N, Watanabe N, Kanuka H and Karasuyama H: The skin is an important bulwark of acquired immunity against intestinal helminths. J Exp Med 210: 2583-2595, 2013.

86. Minutti CM, Jackson-Jones LH, Garcia-Fojeda B, Knipper JA, Sutherland TE, Logan N, Ringqvist E, Guillamat-Prats R, Ferenbach DA, Artigas A, et al: Local amplifiers of IL-4R $\alpha$-mediated macrophage activation promote repair in lung and liver. Science 356: 1076-1080, 2017.

87. Chen S, Kammerl IE, Vosyka O, Baumann T, Yu Y, Wu Y, Irmler M, Overkleeft HS, Beckers J, Eickelberg O, et al: Immunoproteasome dysfunction augments alternative polarization of alveolar macrophages. Cell Death Differ 23: 1026-1037, 2016.

88. Kim J, Chang Y, Bae B, Sohn KH, Cho SH, Chung DH, Kang HR and Kim HY: Innate immune crosstalk in asthmatic airways: Innate lymphoid cells coordinate polarization of lung macrophages. J Allergy Clin Immunol 143: 1769-1782.e11, 2019.

89. King SD and Chen SY: Recent progress on surfactant protein A: cellular function in lung and kidney disease development. Am J Physiol Cell Physiol 319: C316-C320, 2020.

90. Buckley S, Bui KC, Hussain M and Warburton D: Dynamics of TGF-beta 3 peptide activity during rat alveolar epithelial cell proliferative recovery from acute hyperoxia. Am J Physiol 271: L54-L60, 1996.

91. Lechner AJ, Driver IH, Lee J, Conroy CM, Nagle A, Locksley RM and Rock JR: Recruited monocytes and type 2 immunity promote lung regeneration following pneumonectomy. Cell Stem Cell 21: 120-134.e7, 2017.

92. Rindler TN, Stockman CA, Filuta AL, Brown KM, Snowball JM, Zhou W, Veldhuizen R, Zink EM, Dautel SE, Clair G, et al: Alveolar injury and regeneration following deletion of ABCA3. JCI Insight 2: e97381, 2017.

93. Kurowska-Stolarska M, Stolarski B, Kewin P, Murphy G, Corrigan CJ, Ying S, Pitman N, Mirchandani A, Rana B, van Rooijen N, et al: IL-33 amplifies the polarization of alternatively activated macrophages that contribute to airway inflammation. J Immunol 183: 6469-6477, 2009.

94. Cohen M, Giladi A, Gorki AD, Solodkin DG, Zada M, Hladik A, Miklosi A, Salame TM, Halpern KB, David E, et al: Lung single-cell signaling interaction map reveals basophil role in macrophage imprinting. Cell 175: 1031-1044.e18, 2018.

95. Dagher R, Copenhaver AM, Besnard V, Berlin A, Hamidi F, Maret M, Wang J, Qu X, Shrestha Y, Wu J, et al: IL-33-ST2 axis regulates myeloid cell differentiation and activation enabling effective club cell regeneration. Nat Commun 11: 4786, 2020.

96. Silva JD, Su Y, Calfee CS, Delucchi KL, Weiss D, McAuley DF, O'Kane C and Krasnodembskaya AD: MSC extracellular vesicles rescue mitochondrial dysfunction and improve barrier integrity in clinically relevant models of ARDS. Eur Respir J: Dec 17, 2020 (Epub ahead of print). doi: 10.1183/139 93003.02978-2020. 
97. Duan F, Guo L, Yang L, Han Y, Thakur A, Nilsson-Payant BE, Wang P, Zhang Z, Ma CY, Zhou X, et al: Modeling COVID-19 with human pluripotent stem cell-derived cells reveals synergistic effects of anti-inflammatory macrophages with ACE2 inhibition against SARS-CoV-2. Res Sq: Aug 20, 2020 (Epub ahead of print). doi: 10.21203/rs.3.rs-62758/v1.

98. Sersar SI, Elnahas HA, Saleh AB, Moussa SA and Ghafar WA: Pulmonary parasitosis: Applied clinical and therapeutic issues. Heart Lung Circ 15: 24-29, 2006.

99. Miller MM and Reinhardt RL: The heterogeneity, origins, and impact of migratory iILC2 cells in anti-helminth immunity. Front Immunol 11: 1594, 2020.

100. Meiners J, Reitz M, Rudiger N, Turner JE, Heepmann L, Rudolf L, Hartmann W, McSorley HJ and Breloer M: IL-33 facilitates rapid expulsion of the parasitic nematode Strongyloides ratti from the intestine via ILC2- and IL-9-driven mast cell activation. PLoS Pathog 16: e1009121, 2020.

101. Webb LM and Tait Wojno ED: The role of rare innate immune cells in Type 2 immune activation against parasitic helminths. Parasitology 144: 1288-1301, 2017.

102. Bouchery T, Kyle R, Camberis M, Shepherd A, Filbey K, Smith A, Harvie M, Painter G, Johnston K, Ferguson P, et al: ILC2s and T cells cooperate to ensure maintenance of M2 macrophages for lung immunity against hookworms. Nat Commun 6: 6970, 2015.

103. Nieves W, Hung LY, Oniskey TK, Boon L, Foretz M, Viollet B and Herbert DR: Myeloid-restricted AMPK $\alpha 1$ promotes host immunity and protects against IL-12/23p40-dependent lung injury during hookworm infection. J Immunol 196: 4632-4640, 2016.

104. Thawer S, Auret J, Schnoeller C, Chetty A, Smith K, Darby M, Roberts L, Mackay RM, Whitwell HJ, Timms JF, et al: Surfactant protein-D is essential for immunity to helminth infection. PLoS Pathog 12: e1005461, 2016.

105. Snietura M, Brewczynski A, Kopec A and Rutkowski T: Infiltrates of M2-like tumour-associated macrophages are adverse prognostic factor in patients with human papillomavirus-negative but not in human papillomavirus-positive oropharyngeal squamous cell carcinoma. Pathobiology 87 $75-86,2020$

106. Yan C, Wu J, Xu N, Li J,Zhou QY, Yang HM, Cheng XD, Liu JX, Dong X, Koda S, et al: TLR4 deficiency exacerbates biliary injuries and peribiliary fibrosis caused by clonorchis sinensis in a resistant mouse strain. Front Cell Infect Microbiol 10: 526997 2021.

107. Wang H, Zhang CS, Fang BB, Hou J, Li WD, Li ZD, Li L, Bi XJ, Li L, Abulizi A, et al: Dual role of hepatic macrophages in the establishment of the echinococcus multilocularis metacestode in mice. Front Immunol 11: 600635, 2021

108. Kindermann M, Knipfer L, Obermeyer S, Muller U, Alber G, Bogdan C, Schleicher U, Neurath MF and Wirtz S: Group 2 innate lymphoid cells (ILC2) suppress beneficial type 1 immune responses during pulmonary cryptococcosis. Front Immunol 11: 209, 2020

109. Han M, Ishikawa T, Bermick JR, Rajput C, Lei J, Goldsmith AM, Jarman CR, Lee J, Bentley JK and Hershenson MB: IL-1 $\beta$ prevents ILC2 expansion, type 2 cytokine secretion, and mucus metaplasia in response to early-life rhinovirus infection in mice. Allergy 75: 2005-2019, 2020.

110. Yamaguchi M, Samuchiwal SK, Quehenberger O, Boyce JA and Balestrieri B: Macrophages regulate lung ILC2 activation via Pla2g5-dependent mechanisms. Mucosal Immunol 11: 615-626, 2018.

111. Panova V,Gogoi M,Rodriguez-RodriguezN,Sivasubramaniam M, Jolin HE, Heycock MWD, Walker JA, Rana BM, Drynan LF, Hodskinson M, et al: Group-2 innate lymphoid cell-dependent regulation of tissue neutrophil migration by alternatively activated macrophage-secreted Ear11. Mucosal Immunol 14: 26-37, 2020.

112. Wu K, Byers DE, Jin X, Agapov E, Alexander-Brett J, Patel AC, Cella M, Gilfilan S, Colonna M, Kober DL, et al: TREM-2 promotes macrophage survival and lung disease after respiratory viral infection. J Exp Med 212: 681-697, 2015.

113. Botelho F, Dubey A, Ayaub EA, Park R, Yip A, Humbles A, Kolbeck R and Richards CD: IL-33 mediates lung inflammation by the IL-6-type cytokine oncostatin M. Mediators Inflamm 2020: 4087315, 2020.

114. Pei W, Zhang Y, Li X, Luo M, Chen T, Zhang M, Zhong M and Lv K: LncRNA AK085865 depletion ameliorates asthmatic airway inflammation by modulating macrophage polarization. Int Immunopharmacol 83: 106450, 2020.
115. Cai H, Wang J, Mo Y, Ye L, Zhu G, Song X, Zhu M, Xue X, Yang $C$ and Jin $M$ : Salidroside suppresses group 2 innate lymphoid cell-mediated allergic airway inflammation by targeting IL-33/ST2 axis. Int Immunopharmacol 81: 106243, 2020.

116. Nagashima R, Kosai H, Masuo M, Izumiyama K, Noshikawaji $T$, Morimoto M, Kumaki S, Miyazaki Y, Motohashi H, Yamamoto $M$ and Tanaka N: Nrf2 suppresses allergic lung inflammation by attenuating the type 2 innate lymphoid cell response. J Immunol 202: 1331-1339, 2019.

117. Bando JK, Nussbaum JC, Liang HE and Locksley RM: Type 2 innate lymphoid cells constitutively express arginase-I in the naive and inflamed lung. J Leukoc Biol 94: 877-884, 2013.

118. Li Q, Li D, Zhang X, Wan Q, Zhang W, Zheng M, Zou L, Elly C, Lee JH and Liu YC: E3 Ligase VHL promotes group 2 innate lymphoid cell maturation and function via glycolysis inhibition and induction of interleukin-33 receptor. Immunity 48: 258-270. e5, 2018

119. Liu J, Qiu P, Qin J, Wu X, Wang X, Yang X, Li B, Zhang W, Ye K, Peng Z and Lu X: Allogeneic adipose-derived stem cells promote ischemic muscle repair by inducing M2 macrophage polarization via the HIF-1 $\alpha /$ IL-10 pathway. Stem Cells 38: 1307-1320, 2020.

120. Scoville DK, Nolin JD, Ogden HL, An D, Afsharinejad Z, Johnson BW, BammlerTK, Gao X, Frevert CW, AltemeierWA, et al Quantum dots and mouse strain influence house dust mite-induced allergic airway disease. Toxicol Appl Pharmacol 368: 55-62, 2019.

121. Schuijs MJ, Hammad H and Lambrecht BN: Professional and 'Amateur' Antigen-presenting cells in type 2 immunity. Trends Immunol 40: 22-34, 2019.

122. Li D, Guabiraba R, Besnard AG, Komai-Koma M, Jabir MS Zhang L, Graham GJ, Kurowska-Stolarska M, Liew FY, McSharry C and Xu D: IL-33 promotes ST2-dependent lung fibrosis by the induction of alternatively activated macrophages and innate lymphoid cells in mice. J Allergy Clin Immunol 134: 1422-1432.e11, 2014.

123. Park HJ, Chi GY, Choi YH and Park SH: Lupeol suppresses plasminogen activator inhibitor-1-mediated macrophage recruitment and attenuates M2 macrophage polarization. Biochem Biophys Res Commun 527: 889-895, 2020.

124. Zhao Y, De Los Santos FG, Wu Z, Liu T and Phan SH: An ST2-dependent role of bone marrow-derived group 2 innate lymphoid cells in pulmonary fibrosis. J Pathol 245: 399-409, 2018 .

125. Hams E, Armstrong ME, Barlow JL, Saunders SP, Schwartz C, Cooke G, Fahy RJ, Crotty TB, Hirani N, Flynn RJ, et al: IL-25 and type 2 innate lymphoid cells induce pulmonary fibrosis. Proc Natl Acad Sci USA 111: 367-372, 2014.

126. De Grove KC, Provoost S, Verhamme FM, Bracke KR, Joos GF, Maes T and Brusselle GG: Characterization and quantification of innate lymphoid cell subsets in human lung. PLoS One 11: e0145961, 2016

127. Pouwels SD, Zijlstra GJ, van der Toorn M, Hesse L, Gras R, Ten Hacken NH, Krysko DV, Vandenabeele P, de Vries M, van Oosterhout AJ, et al: Cigarette smoke-induced necroptosis and DAMP release trigger neutrophilic airway inflammation in mice. Am J Physiol Lung Cell Mol Physiol 310: L377-L386, 2016.

128. Hershenson MB: Rhinovirus-induced exacerbations of asthma and COPD. Scientifica (Cairo) 2013: 405876, 2013.

129. Zou SC, Pang LL, Mao QS, Wu SY and Xiao QF: IL-9 exacerbates the development of chronic obstructive pulmonary disease through oxidative stress. Eur Rev Med Pharmacol Sci 22: 8877-8884, 2018.

130. Wei Q, Sha Y, Bhattacharya A, Abdel Fattah E, Bonilla D, Jyothula SS, Pandit L, Khurana Hershey GK and Eissa NT: Regulation of IL-4 receptor signaling by STUB1 in lung inflammation. Am J Respir Crit Care Med 189: 16-29, 2014.

131. Saha J, Sarkar D, Pramanik A, Mahanti K, Adhikary A and Bhattacharyya S: PGE2-HIF1 $\alpha$ reciprocal induction regulates migration, phenotypic alteration and immunosuppressive capacity of macrophages in tumor microenvironment. Life Sci 253: 117731, 2020.

132. Lu Q, Wang X, Zhu J, Fei X, Chen H and Li C: Hypoxic tumor-derived exosomal Circ0048117 facilitates M2 macrophage polarization acting as miR-140 sponge in esophageal squamous cell carcinoma. Onco Targets Ther 13: 11883-11897, 2020.

133. Cui W, Zhang W, Yuan X, Liu S, Li M, Niu J, Zhang P and Li D: Vitamin A deficiency execrates Lewis lung carcinoma via induction of type 2 innate lymphoid cells and alternatively activates macrophages. Food Sci Nutr 7: 1288-1294, 2019. 
134. Robbins SM and Senger DL: To promote or inhibit glioma progression, that is the question for IL-33. Cell Stress 5: 19-22, 2020.

135. Mai S, Liu L, Jiang J, Ren P, Diao D, Wang H and Cai K: Oesophageal squamous cell carcinoma-associated IL-33 rewires macrophage polarization towards M2 via activating ornithine decarboxylase. Cell Prolif 54: e12960, 2021.

136. Li J, Razumilava N, Gores GJ, Walters S, Mizuochi T, Mourya R, Bessho K, Wang YH, Glaser SS, Shivakumar P and Bezerra JA: Biliary repair and carcinogenesis are mediated by IL-33-dependent cholangiocyte proliferation. J Clin Invest 124: 3241-3251, 2014.

137. Yang Y, Xia S, Zhang L, Wang W, Chen L and Zhan W: MiR-324-5p/PTPRD/CEBPD axis promotes papillary thyroid carcinoma progression via microenvironment alteration. Cancer Biol Ther 21: 522-532, 2020

138. You Y, Zhang X, Wang X, Yue D, Meng F, Zhu J, Wang Y and Sun X: ILC2 Proliferated by IL-33 stimulation alleviates acute colitis in Rag1(-/-) Mouse through promoting M2 macrophage polarization. J Immunol Res 2020: 5018975, 2020.

139. Della Valle L, Gatta A, Farinelli A, Scarano G, Lumaca A, Tinari N, Cipollone F, Paganelli R and Di Gioacchino M: Allergooncology: An expanding research area. J Biol Regul Homeost Agents 34: 319-326, 2020.
140. Park HJ, Chi GY, Choi YH and Park SH: The root bark of Morus alba L. regulates tumor-associated macrophages by blocking recruitment and M2 polarization of macrophages. Phytother Res 34: 3333-3344, 2020

141. Esposito S, De Simone G, Boccia G, De Caro F and Pagliano P: Sepsis and septic shock: New definitions, new diagnostic and therapeutic approaches. J Glob Antimicrob Resist 10: 204-212, 2017.

142. Xu H, Xu J, Xu L, Jin S, Turnquist HR, Hoffman R, Loughran P, Billiar TR and Deng M: Interleukin-33 contributes to ILC2 activation and early inflammation-associated lung injury during abdominal sepsis. Immunol Cell Biol 96: 935-947, 2018.

143. Nascimento DC, Melo PH, Pineros AR, Ferreira RG, Colon DF, Donate PB, Castanheira FV, Gozzi A, Czaikoski PG, Niedbala W, et al: IL-33 contributes to sepsis-induced long-term immunosuppression by expanding the regulatory $\mathrm{T}$ cell population. Nat Commun 8: 14919, 2017.

This work is licensed under a Creative Commons Attribution-NonCommercial-NoDerivatives 4.0 International (CC BY-NC-ND 4.0) License. 